\title{
Cell-Autonomous and Non-Cell-Autonomous Neuroprotective Functions of ROR $\alpha$ in Neurons and Astrocytes during Hypoxia
}

\author{
Sarah Jolly, ${ }^{1,2}$ Nathalie Journiac, ${ }^{1,2}$ Frédéric Naudet, ${ }^{1,2}$ Vanessa Gautheron, ${ }^{1,2}$ Jean Mariani, ${ }^{1,2,3 *}$ \\ and Béatrice Vernet-der Garabedian ${ }^{1,2 *}$ \\ ${ }^{1}$ CNRS, UMR7102, Paris, F75005, France, ${ }^{2}$ Université Pierre et Marie Curie-P6, UMR7102, Paris, F75005, France, and ${ }^{3}$ Hôpital Charles Foix, Institut de la \\ Longévité, 94205 Ivry-Sur-Seine, France
}

There is increasing evidence to suggest that the neuronal response to hypoxia is regulated through their interactions with astrocytes. However, the hypoxia-induced molecular mechanisms within astrocytes which influence neuronal death have yet to be characterized. In this study, we investigated the roles of the nuclear receptor $\operatorname{ROR} \alpha$ (retinoid-related orphan receptor- $\alpha$ ) respectively in neurons and astrocytes during hypoxia using cultures and cocultures of neurons and astrocytes obtained from ROR $\alpha$-deficient mice. We found that loss of $\operatorname{ROR} \alpha$ function in neuronal cultures increases neuronal death after hypoxia, suggesting a cell-autonomous neuroprotective effect of $\operatorname{ROR} \alpha$. Moreover, wild-type neurons cocultured with $\operatorname{ROR} \alpha$-deficient astrocytes are characterized by a higher death rate after hypoxia than neurons cocultured with wild-type astrocytes, suggesting that $\mathrm{ROR} \alpha$ also has a non-cell-autonomous action. By using cocultures of neurons and astrocytes of different genotypes, we showed that this neuroprotective effect of ROR $\alpha$ in astrocytes is additive to its effect in neurons, and is mediated in part by cell-to-cell interactions between neurons and astrocytes. We also found that ROR $\alpha$ is upregulated by hypoxia in both neurons and astrocytes. Furthermore, our data showed that $\mathrm{ROR} \alpha$ does not alter oxidative mechanisms during hypoxia but regulates hypoxic inducible factor $1 \alpha$ (HIF-1 $\alpha$ ) expression, a major regulator of hypoxia sensing, in a cell-specific manner. Indeed, the neuroprotective function of ROR $\alpha$ in astrocytes correlates with a downregulation of HIF- $1 \alpha$ selectively in these cells. Altogether, our results show that $\mathrm{ROR} \alpha$ is a key molecular player in hypoxia, protecting neurons through its dual action in neurons and astrocytes.

\section{Introduction}

Hypoxia is a deficiency of available oxygen that can lead to neuronal death and cause severe brain damage. Astrocytes are intimately involved in the neuronal response to hypoxia and play an important role in many aspects of hypoxia: the regulation of glucose metabolism, transmitter release, inflammatory processes, and release of neuroprotectants (for review, see Zhao and Rempe, 2010). However, we are only beginning to understand the conditions under which these functions are neuroprotective or deleterious. Hypoxic inducible factor 1 (HIF-1) is a key element induced during hypoxia (Semenza, 2000). This transcription factor is a heterodimer of HIF- $1 \beta$, which is constitutively active, and HIF- $1 \alpha$, which is stabilized and activated only during

\footnotetext{
Received March 22, 2011; revised Aug. 1, 2011; accepted Aug. 12, 2011

Author contributions:S.J., J.M., and B.V.-d.G. designed research;S.J., N.J., F.N., and V.G. performed research;S.J., N.J., J.M., and B.V.-d.G. analyzed data; S.J., J.M., and B.V.-d.G. wrote the paper.

This work was supported by funds from the Centre National de la Recherche Scientifique (CNRS) and Université Pierre et Marie Curie (France). S.J. was supported by fellowships from the Délégation Générale pour I'Armement, the CNRS, and the Association pour la Recherche sur le Cancer (ARC). N.J. was supported by the Neuropôle de Recherche Francilien, and the lle de France region. We thank Dr. Fekrije Selimi and Dr. Frédéric Flamant for critical reading of this manuscript. We thank Dr. Florence Frédéric for her assistance with statistical analysis. We thank the Cell Imaging and Flow Cytometry facility of the IFR83 (Paris, France) for access and technical support in microscopy.

*J.M. and B.V.-d.G. contributed equally to this work.

Correspondence should be addressed to either Sarah Jolly or Béatrice Vernet-der Garabedian, DVSN lab, UMR7102, Case 14, UPMC, 9 quai Saint Bernard, 75005 Paris, France, E-mail: sarahjolly@hotmail.fr or bvernet@snv.jussieu.fr.

DOI:10.1523/JNEUROSCI.1443-11.2011

Copyright $\odot 2011$ the authors $\quad 0270-6474 / 11 / 3114314-10 \$ 15.00 / 0$
}

hypoxia (Bruick and McKnight, 2001; Jaakkola et al., 2001; Lando et al., 2002). In the brain, HIF1 $\alpha$ production is induced by hypoxia in neurons, astrocytes, ependymal and, possibly, endothelial cells (Chávez et al., 2000). HIF-1 regulates several genes, including Vegf (vascular endothelial growth factor), Nip3 (BCL2/ adenovirus E1B $19 \mathrm{kDa}$ interacting protein 3 ) and $\mathrm{Hk} 2$ (hexokinase 2) (Sharp and Bernaudin, 2004). The transcription factor retinoid-related orphan receptor- $\alpha(\operatorname{ROR} \alpha)$ has been shown also to be a target of HIF- $1 \alpha$ (Chauvet et al., 2004; Miki et al., 2004). Moreover, ROR $\alpha$ expression is increased by hypoxia in various cell lines (Chauvet et al., 2002; Miki et al., 2004; Kim et al., 2008).

ROR $\alpha$ belongs to the nuclear receptor family and is considered to be a constitutive activator of transcription. Sterol derivatives such as cholesterol and hydroxycholesterol have recently been identified as potential ligands for $\operatorname{ROR} \alpha$ (Kallen et al., 2002; Wang et al., 2010). In the brain, $\mathrm{ROR} \alpha$ is expressed in neurons in the cortex, cerebellum, inferior olivary nucleus, hippocampus, thalamus, hypothalamus, olfactory bulb, and retina (Ino, 2004). We also recently reported the nuclear expression of ROR $\alpha$ in astrocytes, particularly in the hippocampus, cortex, and cerebellum (Journiac et al., 2009). There is a natural mutant mouse for $\operatorname{ROR} \alpha$, called staggerer, which carries a 122 bp deletion in the ligand-binding domain (LBD) of the Rora gene (Hamilton et al., 1996). The principal CNS phenotype of this mouse is extensive cerebellar neurodegeneration resulting in severe ataxia (Gold et al., 2007). In addition to its function in the cerebellum, $\operatorname{ROR} \alpha$ has 
other important functions in the CNS including a neuroprotective role in cortical neurons (Boukhtouche et al., 2006). The upregulation of $\operatorname{ROR} \alpha$ expression during hypoxia and its neuroprotective function raise questions about the possible role of neuronal and/or astrocyte $\operatorname{ROR} \alpha$ in neuroprotective mechanisms during hypoxia in the cortex.

In this study, we focused on the function of $\operatorname{ROR} \alpha$ in neurons and astrocytes following hypoxia using $\operatorname{ROR} \alpha$-deficient cultures and cocultures of neurons and astrocytes. We show that $\operatorname{ROR} \alpha$ has a neuroprotective function during hypoxia not only in neurons but also through its action in astrocytes. We also demonstrate the upregulation of $\operatorname{ROR} \alpha$ expression by hypoxia in cortical neurons and astrocytes. Finally, we show that $\operatorname{ROR} \alpha$ selectively inhibits HIF- $1 \alpha$ expression in astrocytes. These results demonstrate that $\operatorname{ROR} \alpha$ present in both neurons and astrocytes plays a crucial role in hypoxia.

\section{Materials and Methods}

\section{Animals and genotyping}

All efforts were made to minimize animal suffering and the number of animals used. All animal procedures were performed according to the regulations of the Comite National d'Ethique pour les Sciences de la Vie et de la Santé, in accordance with the European Communities Council Directive (86/609/EEC). Protocols were approved by the Comite regional d'éthique de Paris (file number p3/2008/026). Homozygous staggerer mice $\left(\right.$ Rora $\left.^{\mathrm{sg} / \mathrm{sg}}\right)$ and their control wild-type $\left(\mathrm{Rora}^{+/+}\right)$littermates were obtained by crossing heterozygous mice $\left(\mathrm{Rora}^{+/ s g}\right)$. Mice were maintained on a common homogeneous genetic background (C57BL/ 6J) in our animal facilities at the Université Pierre et Marie Curie. Mice were genotyped for the staggerer mutation as previously described (Doulazmi et al., 1999).

\section{Primary cortical neuron culture}

Neuronal cultures were prepared from the neocortex of 14-d-old embryos of C57BL/6J (Janvier) or staggerer mice of either sex. Meninges were removed and the cerebral cortices were dissected. The tissue was then incubated with $0.25 \%$ trypsin-EDTA (Eurobio) and DNase I (50 $\mu \mathrm{g} / \mathrm{ml}$, Sigma-Aldrich) for $10 \mathrm{~min}$ at $37^{\circ} \mathrm{C}$. The cells were mechanically dissociated, washed three times in DMEM and plated on poly-D-lysine $\left(0.1 \mathrm{mg} / \mathrm{ml}\right.$, Sigma)-coated culture wells at a density of $1.75 \times 10^{5}$ cells $/ \mathrm{cm}^{2}$. The cultures were maintained in DMEM supplemented with Glutamax, 5\% heat-inactivated fetal bovine serum (FBS) (BioWest), N-2 and B-27 supplements (Invitrogen), and penicillin/streptomycin (Invitrogen). After 3 days in vitro (DIV 3), one third of the medium was removed and replaced with fresh medium containing $3 \mu \mathrm{M}$ Ara C (cytosine $\beta$-D-arabinofuranoside, Sigma) to inhibit the growth of dividing cells such as astrocytes and microglia. The cultures were maintained in a humidified incubator at $37^{\circ} \mathrm{C}$ under an atmosphere containing $5 \% \mathrm{CO}_{2}$. Neuronal cultures were used for experimentation on DIV 7. The purity of neuronal cultures was checked by immunolabeling with antibodies directed against neurons (mouse anti-NeuN, 1:250, Millipore Bioscience Research Reagents; anti-MAP2, 1:500, Millipore), and against astrocytes (mouse anti-GFAP-CY3, 1:1000, Sigma). Cells fixed in 4\% PFA were labeled after membrane permeabilization and saturation with PBS supplemented with $0.25 \%$ Triton X-100 (Sigma), $0.2 \%$ gelatin, $0.1 \%$ sodium azide (buffer A) and $0.1 \mathrm{~m}$ lysine. Nuclei were stained with Hoechst 33258 (Sigma). The cultures contained $>95 \%$ neurons.

\section{Cortical astrocyte culture}

Highly purified astrocyte cultures were prepared from 1- or 2-d-old pups of C57BL/6J or staggerer mice of either sex. Cerebral cortices were dissected and the meningeal tissue was carefully stripped off. The tissue was then incubated with $0.25 \%$ trypsin-EDTA and DNase I ( $50 \mu \mathrm{g} / \mathrm{ml})$ for 10 $\mathrm{min}$ at $37^{\circ} \mathrm{C}$. The cells were mechanically dissociated, washed three times in DMEM and plated in culture wells at a density of 1 cortex $/ 75 \mathrm{~cm}^{2}$. The cultures were maintained in DMEM supplemented with glucose $(1 \mathrm{~g} / \mathrm{L})$, $10 \%$ heat-inactivated FBS, $1 \mathrm{~mm}$ L-glutamine (Seromed), $50 \mathrm{ng} / \mathrm{ml}$ gentamicin (Invitrogen) and incubated at $37^{\circ} \mathrm{C}$ in a humidified atmosphere containing $5 \% \mathrm{CO}_{2} / 95 \%$ air. The medium was changed twice weekly. On DIV 7, astrocytes were treated with trypsin. For experiments on pure astrocyte cultures, cells were plated directly in 24- or six-well plates. For coculture experiments, cells were plated on glass coverslips treated with $0.5 \mathrm{mg} / \mathrm{ml}$ poly-D-lysine (P0899, Sigma) in six-well dishes. The cultures were then maintained in a humidified incubator for 1 week. The purity of astrocyte cultures was checked by immunolabeling with antibodies directed against neurons (mouse anti-NeuN), astrocytes (mouse antiGFAP-CY3, rabbit anti-s100 Sigma) and microglial cells (rabbit antiIbal, Wako). Cells fixed in 4\% PFA were labeled after membrane permeabilization and saturation with Buffer A and $0.1 \mathrm{M}$ lysine. Nuclei were stained with Hoechst 33258 (Sigma). Contamination with other cells never exceeded 3\%.

\section{Neuron and astrocyte cocultures}

Embryonic cortical Rora ${ }^{s g / s g}$ or Rora $^{+/+}$neurons were cocultured with Rora $^{s g / s g}$ or Rora ${ }^{+/+}$astrocyte monolayers. A neuronal suspension was prepared from the neocortex of 14-d-old embryos of C57BL/6J or staggerer mice, as described above. One day before the plating of neurons, astrocytes were maintained in neuronal medium (DMEM supplemented with Glutamax, 5\% FBS, N-2 and B-27 supplements, and penicillin/ streptomycin). Neurons were plated directly on the surface of the confluent astrocyte monolayers at a density of $4 \times 10^{4}$ cells $/ \mathrm{cm}^{2}$. On DIV 3 for the neurons, one third of the medium was removed and replaced with fresh medium containing $3 \mu \mathrm{M}$ Ara C (Sigma). The cultures were maintained in a humidified incubator at $37^{\circ} \mathrm{C}$, under an atmosphere containing $5 \% \mathrm{CO}_{2}$. The cocultures were used for experimentation when the neurons had been in culture for 7 or $8 \mathrm{~d}$. The purity of cocultures was checked by immunocytochemistry.

For cocultures without contact between neurons and astrocytes, we used the same protocol except that astrocytes were grown on an insert placed in the culture wells. The cell culture inserts (35-3102, Falcon) had $1 \mu \mathrm{m}$ pores. Neurons were plated on poly-D-lysine $(0.1 \mathrm{mg} / \mathrm{ml}$, Sigma)coated culture wells at a density of $1.75 \times 10^{5} \mathrm{cells} / \mathrm{cm}^{2}$.

\section{Hypoxia treatment paradigms}

Cultures were exposed to hypoxia in a triple gas incubator in which oxygen was replaced with nitrogen to achieve a concentration of $1 \%$ oxygen (Thermo Electron) for various periods of time. Hypoxia was terminated by returning the cells to normoxic conditions (reoxygenation) for various lengths of time. As a control, sister cultures maintained in normoxic conditions were analyzed in parallel.

\section{Neurite outgrowth analysis in pure cultures and cocultures}

Cortical neurons (DIV 3) cultured in 24-well dishes were transfected with the pmaxCloning vector (Amaxa) containing the GFP coding sequence under the control of the CMV promoter. We incubated $2 \mu \mathrm{l}$ of Lipofectamine 2000 (Invitrogen) in $50 \mu$ l of DMEM (Invitrogen) for 5 min at room temperature and added an equal volume of DMEM containing $0.1 \mu \mathrm{g}$ of DNA. The DNA/Lipofectamine mixture was incubated at room temperature for $20 \mathrm{~min}$ and added to the neurons. The transfection mixture was then incubated for $90 \mathrm{~min}$ at $37^{\circ} \mathrm{C}$, after which it was replaced with the original medium. After $48 \mathrm{~h}$, cells were fixed in $4 \% \mathrm{PFA}$ and nuclei were stained with Hoechst 33258 (GFP was visible in $\sim 1 \%$ of the neurons). GFP-transfected neurons were observed under a Nikon Eclipse E600 microscope and photographed with a LEICA SP5 confocal microscope. All dendrites were traced with the NeuronJ plug-in of NIH ImageJ software. In all experiments, neurons were selected at random for photography and the neurites were photographed, traced and analyzed by an investigator blind to the details of the sample analyzed. Dendritic complexity was quantified by measuring the dendrite length and counting the number of dendrites for each order of branching. The primary dendrites were defined as those emanating directly from the soma. Higher-order branches were defined as those arising from the processes of the previous order. The dendrite length for a particular order of branching was calculated by averaging the lengths of all dendrites for that order of branching. The number of dendrites in a given order of branching was calculated by averaging the number of dendrites for each order of branching. 
Neuronal viability assays

MTT. For experiments on neurons, cell survival was assessed with the MTT (3-(4,5-dimethylthiazol-2-yl)-2,5-diphenyltetrazolium bromide) assay. The conversion of the yellow tetrazolium salt, MTT, to the purple formazan dye is dependent on mitochondrial activity. We added $100 \mu \mathrm{l}$ of a stock solution of MTT (M5655-1G, $5 \mathrm{mg} / \mathrm{ml}$ in PBS, Sigma) to $900 \mu \mathrm{l}$ of culture medium/well, and incubated the mixture for $4 \mathrm{~h}$ in a humidified atmosphere at $37^{\circ} \mathrm{C}$, under an atmosphere containing $5 \% \mathrm{CO}_{2}$. The cells were then treated with $0.1 \mathrm{M} \mathrm{HCl}$ in isopropanol for $30 \mathrm{~min}$. Reduced MTT levels were determined by measuring absorbance at $560 \mathrm{~nm}$. The effect of hypoxia on cell viability was evaluated by comparing cultures subjected to hypoxia with sister cultures kept in normoxia.

$L D H$. In coculture experiments, cell death was quantified by measuring the amounts of LDH released from damaged cells into the culture medium $24 \mathrm{~h}$ after hypoxia according to the assay manufacturer's instructions (CytoTox 96 Non-Radioactive Cytotoxicity Assay, Promega). LDH levels reflect neuronal death as astrocytes are not killed by hypoxia. Absorbance was read at $490 \mathrm{~nm}$. The maximum LDH release, corresponding to almost complete cell damage, was evaluated after the lysis of all the cells. The percentage of cytotoxicity was calculated by dividing the experimental absorbance value by the absorbance for maximal LDH release, after subtracting background values due to the presence of LDH in the culture medium of cells kept in normoxia. The mean amount of LDH in normoxic cocultures was used as a control. All experiments were performed at least in triplicate and repeated five times with independent cell cultures.

Hoechst staining. After hypoxia and reoxygenation, nuclei were stained with Hoechst 33258 (Sigma). Neuronal and astrocyte viability were assessed by counting living nuclei of neurons (small nuclei with no mark of apoptosis or necrosis) and astrocytes. For each condition, three different wells were counted, three pictures per well were analyzed. Two different counters analyzed the pictures. Analysis was conducted blind to the experimental conditions. Cell survival was expressed as the percentage of living cells in hypoxic groups compared with the number of living cells in sister cultures cultivated in normoxia.

\section{RNA purification and real-time PCR}

Total RNA was extracted from cultures with TRIzol Reagent (Invitrogen) according to the manufacturer's protocol. We checked the concentration and quality of the RNA by spectrophotometry. RNA was treated with DNaseI (Invitrogen) according to the manufacturer's instructions. Complementary DNA was synthesized from $0.5 \mu \mathrm{g}$ of RNA with the HighCapacity cDNA Reverse Transcription Kit (Applied Biosystems). Target cDNA levels were determined by real-time PCR with the Mx3005 unit (Stratagene) using SYBR Green (Abgene) to detect the amplification products. Amplification assays were performed in duplicate in $25 \mu \mathrm{l}$ reaction mixtures containing Absolute QPCR SYBR Green Mix (Abgene), $200 \mathrm{~nm}$ forward and reverse primers and cDNA. PCR was conducted over 40 cycles of $95^{\circ} \mathrm{C}$ for $15 \mathrm{~s}, 58^{\circ} \mathrm{C}$ for $30 \mathrm{~s}$ and $72^{\circ} \mathrm{C}$ for $15 \mathrm{~s}$, preceded by an initial denaturation cycle at $95^{\circ} \mathrm{C}$ for $15 \mathrm{~min}$. The efficiency of amplification was close to $100 \%$ for each set of primer, as estimated with serial dilutions of cDNA. A dissociation curve was generated for each transcript, to check the specificity of the amplification. Arbp (acidic ribosomal phosphoprotein P0) levels were used to normalize the amount of cDNA. Quantification was performed by the comparative $\Delta \Delta C_{\mathrm{t}}$ method as previously described (Pfaffl, 2001). Levels relative to those in nonhypoxic cultures were calculated according to the formula $2^{-\left(\Delta \Delta C_{\mathrm{t}}\right)}$.

\section{Primers}

The Mus musculus primer sequences used are listed in Table 1.

\section{Nuclear protein preparation}

Fractions enriched in nuclear proteins were isolated with a rapid protocol (adapted from the protocol of Rempe et al., 2007). Cultured cells were homogenized and lysed in $10 \mathrm{~mm}$ Tris- $\mathrm{HCl}, \mathrm{pH} 7.6,1.5 \mathrm{~mm} \mathrm{MgCl}_{2}$, $10 \mathrm{~mm} \mathrm{KCl}, 0.5 \mathrm{~mm}$ dithiothreitol (DTT), $0.2 \mathrm{~mm}$ AEBSF (4-(2aminoethyl)benzenesulfonyl fluoride hydrochloride, Sigma) and Protease Inhibitor Cocktail (Sigma). Samples were incubated for $10 \mathrm{~min}$ on ice and centrifuged for $1 \mathrm{~min}$ at $10,000 \times \mathrm{g}$; the supernatants were col-
Table 1. Primer sequences used to amplify mRNA

\begin{tabular}{lll}
\hline Gene & Forward & Reverse \\
\hline Rora & TCCAAATCCACCTGGAAC & GAAGGTCTGCCACGTTATCTG \\
Arbp & TGCCAGCTCAGAACACTGGTCTA & GGGAGATGTTCAGCATGTTCAGCA \\
Hif1a & CGGCGAGCAAAGAGTCTGA & TAGACCACCGGCATCCAGAA \\
Vegf & TGACTGCTGTGGACTTGTG & GAATGGGTTTTCGTGTTC \\
Sod1 & TGGTTCCACGTCCATCAGTA & ACCGTCCTTCCAGCAGTCA \\
Gpx1 & GGGACTACACGAGATGAACGA & ACCATTCACTTCGCACTTCTCA \\
Prdx6 & TGCTGGGATAGCATGGGA & AACCTCTGAGAAGTGCACA \\
Cat & GCGTCCAGTGCGCTGTAGA & TCAGGGTGGACGTCAGTGAA \\
Rorb & TGTGTCGTGCCTTCAACCCATT & TCTCTTCCTCAGTCAGCTGCAA \\
Nip3 & CCTGTCGCAGTTGGGTCGG & TCGTCCAGATTCATGCTGGGCA \\
Hk2 & AGCTGGTGAGCCATCGTGGT & ATCTTGTTGCGGGAGTCGG \\
\hline
\end{tabular}

lected (cytoplasm-enriched fraction). Pellets were resuspended in buffer containing $420 \mathrm{~mm} \mathrm{KCl}, 1.5 \mathrm{~mm} \mathrm{MgCl}_{2}, 25 \%$ glycerol, $0.2 \mathrm{~mm}$ EDTA, 0.5 mм DTT, 0.2 mm AEBSF and Protease Inhibitor Cocktail (Sigma). Samples were vigorously mixed, incubated for $20 \mathrm{~min}$ on ice and centrifuged at $10,000 \times g$ for $5 \mathrm{~min}$. The supernatants enriched in nuclear material were subjected to four rounds of sonication for $30 \mathrm{~s}$. The Bio-Rad DC protein assay was used to determine protein concentration, with bovine serum albumin as the standard.

\section{Western blot analysis}

Denatured proteins in Laemmli buffer $(12.5-50 \mu \mathrm{g})$ were resolved by SDS-PAGE and transferred to an Immobilin-P membrane (Millipore). Nonspecific binding was blocked with PBS/Tween 20 (PBST) supplemented with $5 \%$ nonfat dry milk, for $45 \mathrm{~min}$ at room temperature. Membranes were incubated overnight at $4^{\circ} \mathrm{C}$ in PBST supplemented with $2.5 \%$ nonfat dry milk and the following primary antibodies: goat anti$\operatorname{ROR} \alpha(1: 1000$, Santa Cruz Biotechnology), rabbit anti-HIF- $1 \alpha$ (NB 100$479,1: 1000$, Novus Biologicals), mouse anti- $\beta$-actin (1:10,000, Sigma) antibodies. Membranes were then incubated at room temperature for 30 min in PBST-2.5\% nonfat dry milk with anti-goat (1:200,000, Thermo Fisher Scientific), anti-mouse (1:50,000) or anti-rabbit $(1: 50,000)$ horseradish peroxidase-conjugated secondary antibodies (Jackson ImmunoResearch). The protein bands were detected by enhanced chemiluminescence (SuperSignal West Pico/Dura Extended Duration Substrate, Pierce). All blots were quantified by densitometry with NIH ImageJ software. Relative levels of transcription factors were determined by normalizing the density for the protein of interest with respect to a protein used as a loading control, in this case $\beta$-actin.

\section{Statistical analysis}

Statistical significance was determined with Statview software (Abacus Concepts). All the values in the text and figure legends are means \pm SEM. All error bars on graphs indicate the SEM.

\section{Results}

ROR $\alpha$ has cell-autonomous protective functions in cortical neurons but not in astrocytes subjected to hypoxia

To determine the function of $\operatorname{ROR} \alpha$ in neurons and astrocytes during hypoxia, we used primary cortical culture of neurons and astrocytes with $\left(\mathrm{Rora}^{+/+}\right)$and without $\left(\mathrm{Rora}^{\mathrm{sg} / \mathrm{sg}}\right)$ endogenous $\operatorname{ROR} \alpha$. Neurons were exposed to hypoxia and were then subjected to a $24 \mathrm{~h}$ reoxygenation period (Fig. $1 A$ ). Hypoxia resulted in neuronal death as seen by immunostaining (Fig. $1 B$ ) and, after $14 \mathrm{~h}$ of hypoxia, no neuron survived (data not shown). When cortical neurons were subjected to 8 or $10 \mathrm{~h}$ of hypoxia followed by reoxygenation, Rora $^{s g / s g}$ neurons showed moderately, but significantly lower rates of cell survival (15\%) than Rora $^{+/+}$neurons $(n=4$, Fig. $1 C)$. After $12 \mathrm{~h}$ of hypoxia, neuronal survival rates were also lower when neurons lacked $\operatorname{ROR} \alpha$ but the difference was not significant (Fig. 1C). The loss of $\operatorname{ROR} \alpha$ function in neurons therefore increases susceptibility to hypoxia-induced neuronal death. Astrocytes are more resistant to hypoxia than 


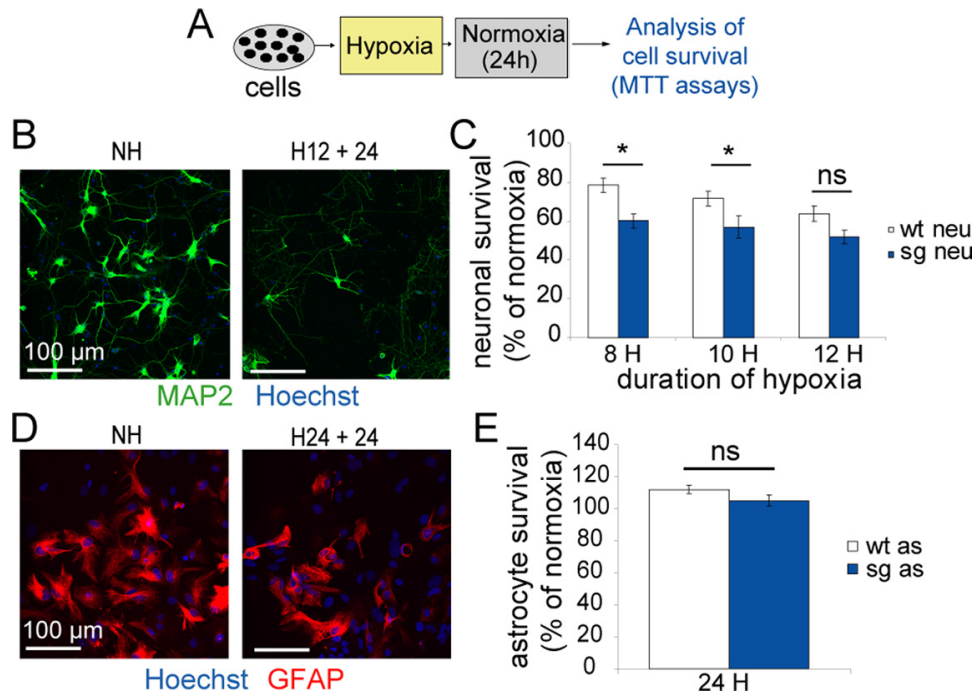

Figure 1. ROR $\alpha$ has a cell-autonomous neuroprotective function in neurons after hypoxia. $\boldsymbol{A}$, Schematic diagram illustrating the experimental protocol: neurons $(\boldsymbol{B}, \boldsymbol{C})$ or astrocytes $(\boldsymbol{D}, \boldsymbol{E})$ (black cells) were subjected to hypoxia followed by $24 \mathrm{~h}$ of normoxia. $\boldsymbol{B}$, Wild-type neurons were labeled with anti-MAP2 (green) antibody and nuclei were labeled with Hoechst 33258 (blue). Immunostaining shows a decrease in cell survival and the fragmentation of neurites after hypoxia $(\mathrm{H} 12+24)$ not observed in neurons kept in normoxia (NH). C, Survival of Rora ${ }^{+/+}$(wt) or Rora $a^{s g / s g}(\mathrm{sg})$ neurons was assessed by an MTT assay after $8-12$ h of hypoxia and $24 \mathrm{~h}$ of reoxygenation. $\boldsymbol{D}$, Wild-type astrocytes were labeled with anti-GFAP (red) antibody and nuclei were labeled with Hoechst 33258 (blue). Hypoxia did not induce the activation of cortical astrocytes. E, Survival of Rora ${ }^{+/+}$(wt) or Rora ${ }^{s g / s g}$ (sg) astrocytes was assessed by an MTT assay after $24 \mathrm{~h}$ of hypoxia and 24 of reoxygenation (24H). Values are the means \pm SEM of 4 independent cultures. ( $t$ test, ${ }^{*} p<0.05$, ns, not significant).

neurons and cortical astrocytes remained alive even after $72 \mathrm{~h}$ of hypoxia followed by $24 \mathrm{~h}$ of reoxygenation (data not shown). After $24 \mathrm{~h}$ of hypoxia, all astrocytes survived and their reactivity was similar (Fig. 1D). After hypoxia, cell survival was similar in Rora $^{+/+}$and Rora $^{\text {sg/sg }}$ astrocytes indicating that the loss of ROR $\alpha$ function does not influence astrocyte survival during hypoxia (Fig. $1 E$ ).

$\operatorname{ROR} \alpha$ has non-cell-autonomous neuroprotective functions in astrocytes subjected to hypoxia

Astrocytes play a key role in physiological and pathological processes in the CNS and are active partners of neurons. Thus, even if the loss of $\operatorname{ROR} \alpha$ function in astrocytes does not influence astrocyte survival after hypoxia, it may affect neuronal survival in a non-cell-autonomous manner. We investigated the effect of the selective loss of $\operatorname{ROR} \alpha$ function in astrocytes on the survival of neurons in normoxia and after hypoxia, in an in vitro model consisting of cocultures of cortical neurons and astrocytes. Cocultures were prepared by combining cells of different genotypes, i.e., Rora $^{+/+}$and Rora $^{\text {sg/sg }}$ astrocytes with Rora $^{+/+}$neurons (Fig. $2 A)$. We first investigated the effect of a lack of $\operatorname{ROR} \alpha$ in astrocytes on neuronal survival and growth in normal conditions. When astrocytes become reactive, they undergo major morphological modifications and one of the principal hallmarks of reactive astrocytes is the upregulation of GFAP. The inhibition of GFAP production in astrocytes has been shown to improve neuronal survival and neurite outgrowth in an in vitro coculture model (Desclaux et al., 2009). We therefore assessed by immunocytochemistry and Western blotting that GFAP levels were similar in Rora $^{+/+}$and Rora ${ }^{s g / s g}$ astrocytes, in both normoxia and hypoxia (data not shown). We then quantified survival of neurons cocultured with Rora $^{+/+}$or Rora ${ }^{\text {sg/sg }}$ astrocytes in normoxia. Survival rates were similar for neurons cocultured with Rora $^{+/+}$ and Rora $^{s g / s g}$ astrocytes $(n=4$, Fig. $2 B$ ). We then investigated the effect of astrocyte genotype on neurite growth by transfecting neurons with GFP (Fig. 2C). Astrocytes of all genotypes promoted dendritic growth, but neurons grown on $\operatorname{ROR} \alpha$-deficient astrocytes occupied a significantly larger area, had more dendrites and a greater total dendrite length (Fig. $2 D, E$ ). ROR $\alpha$ in astrocytes modulated the establishment and maintenance of the dendritic arbor in a non-cell-autonomous manner. This effect is specific to the function of $\operatorname{ROR} \alpha$ in astrocytes as Rora $^{+/+}$and Rora ${ }^{\text {sg/sg }}$ neurons had similar branching patterns, occupied a similar area and had similar numbers of dendrites in vitro (data not shown). Thus the loss of $\operatorname{ROR} \alpha$ in astrocytes has little effect on astrocyte reactivity and properties. Consequently, Rora ${ }^{s g / s g}$ astrocytes provide suitable support for neuronal development.

We next compared the survival of neurons grown on $\mathrm{Rora}^{+/+}$and Rora ${ }^{\text {sg/sg }}$ astrocytes after $6-10 \mathrm{~h}$ of hypoxia and reoxygenation (Fig. $2 F$ ). An analysis of MAP-2-immunostained neurons revealed that neurons grown on $\operatorname{ROR} \alpha$ deficient astrocytes had a lower neuron density and lower levels of neurite after $8 \mathrm{~h}$ of hypoxia than control neurons (Fig. $2 F$ ). Moreover, neuronal death rates after 6 and $8 \mathrm{~h}$ of hypoxia were significantly higher when astrocytes lacked ROR $\alpha$ (LDH experiments, $p<0.05, n=4$, Fig. $2 F$ ). After $10 \mathrm{~h}$ of hypoxia, neuronal death rates were higher when astrocytes lacked ROR $\alpha$ but the difference was not significant (Fig. $2 F$ ). We confirmed these results by quantifying neuronal survival using Hoechst. We found that neurons cocultured with mutant astrocytes had a lower survival rate (40\% lower) compared with neurons cocultured with wild-type astrocytes after $8 \mathrm{~h}$ of hypoxia (Fig. 2F). For the following experiments, we chose to subject cocultures to $8 \mathrm{~h}$ of hypoxia. In conclusion, $\operatorname{ROR} \alpha$ in astrocytes has a non-cell-autonomous neuroprotective effect after hypoxia. Our results suggest that $\operatorname{ROR} \alpha$ has two neuroprotective effects: a cell-autonomous effect in neurons and a non-cell-autonomous effect in astrocytes.

\section{The neuroprotective effects of ROR $\alpha$ in astrocytes and neurons are additive}

We then investigated whether the two neuroprotective effects of $\operatorname{ROR} \alpha$ in neurons and in astrocytes were additive. We used cocultures of cells with different genotypes: Rora ${ }^{+/+}$or Rora ${ }^{s g / s g}$ astrocytes with Rora $^{+/+}$or Rora ${ }^{\text {sg/sg }}$ neurons and compared neuronal death rates after hypoxia and reoxygenation. In cocultures, $\operatorname{ROR} \alpha$ deficient neurons are more susceptible to hypoxia only when astrocytes are also deficient for $\operatorname{ROR} \alpha$. After hypoxia, neuronal death rates were higher when Rora $^{\text {sg/sg }}$ neurons were cocultured with Rora $^{s g / s g}$ astrocytes (55\% higher than for cocultures with Rora $^{+/+}$astrocytes, $n=5$, Fig. $2 G$ ). Moreover, when both neurons and astrocytes lacked $\operatorname{ROR} \alpha$, neuronal death rates were significantly higher than for cocultures of $\operatorname{Rora}^{\mathrm{sg} / \mathrm{sg}}$ astrocytes and Rora $^{+/+}$neurons (30\% higher, $n=5$, Fig. $2 G$ ). In conclusion, the neuroprotective functions of $\operatorname{ROR} \alpha$ in neurons and astrocytes after hypoxia are additive. Given the magnitude and the novelty of the non-cell-autonomous effect of $\operatorname{ROR} \alpha$ in astrocytes, we 

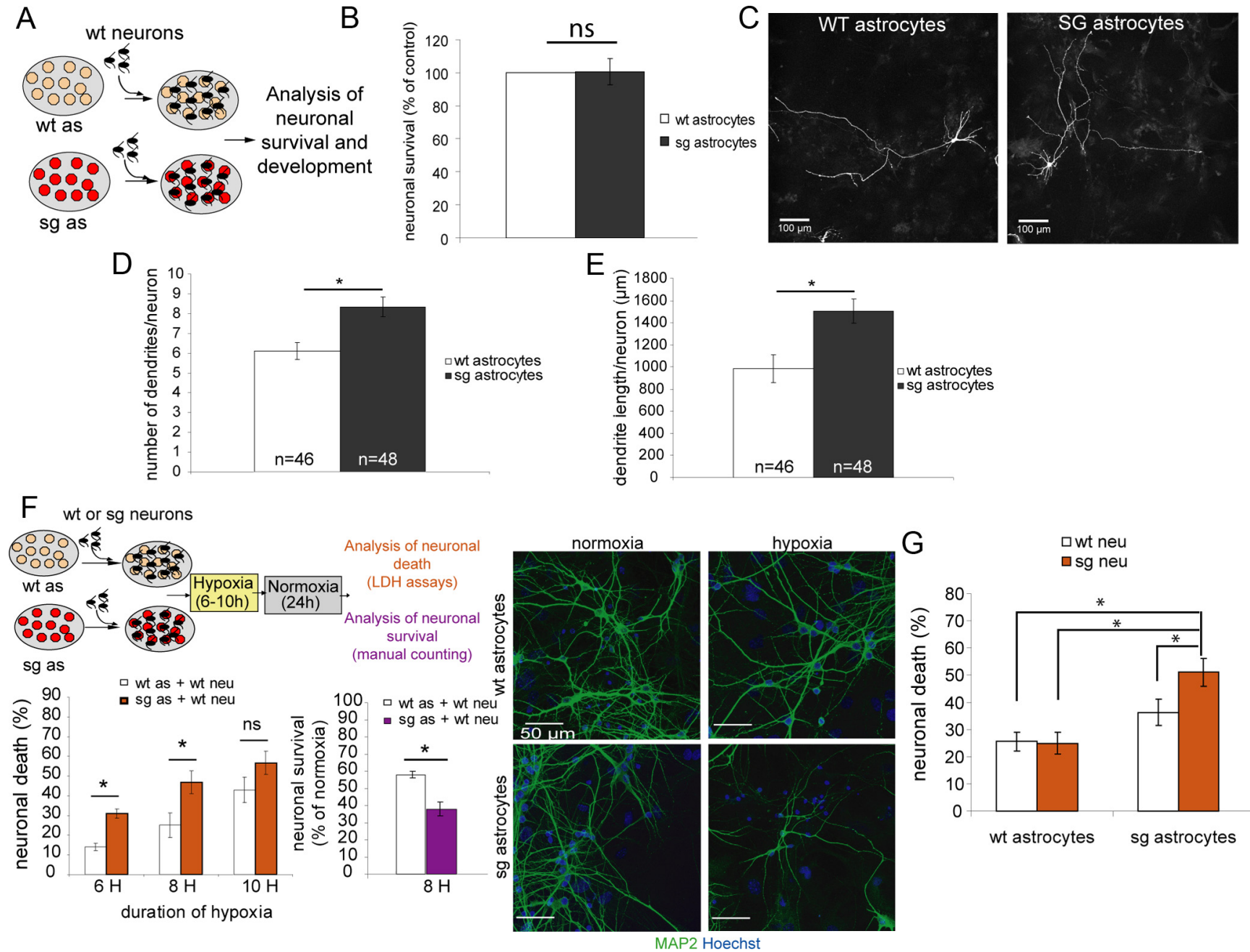

Figure 2. ROR $\alpha$ in astrocytes is neuroprotective in a non-cell-autonomous manner after hypoxia. $\boldsymbol{A}-\boldsymbol{E}$, The loss of ROR $\alpha$ in astrocytes modifies the development of the dendritic arbor of neurons in normoxia. $A$, Schematic diagram illustrating the experimental protocol: Rora ${ }^{+/+}$(wt) neurons (black cells) were plated directly onto a monolayer of Rora ${ }^{+/+}$(wt) or Rora ${ }^{s / / 5 g}(\mathrm{sg}$ ) astrocytes (as; orange and red circles). B, Survival rates of neurons in cocultures with Rora ${ }^{+/+}$or Rora ${ }^{5 g / s g}$ astrocytes were estimated in normoxia. C, Neurons grown on Rora ${ }^{+/+}$or Rora ${ }^{\text {sg/sg }}$ astrocytes were transfected with GFP. D, The number of dendrites per neuron was determined. $\boldsymbol{E}$, The total dendritic length per neuron was determined in each set of culture conditions. Dendrites from the individual neurons (numbers indicated in the bars) in four independent experiments were imaged and analyzed with NeuronJ software. $\boldsymbol{F}$, The loss of ROR $\alpha$ in astrocytes increases the susceptibility of neurons to hypoxia-induced neuronal death. Schematic diagram illustrating the experimental protocol:Rora ${ }^{+/+}$or Rora ${ }^{\text {gg/sg }}$ neurons (black cells) were plated directly onto a monolayer of Rora ${ }^{+/+}$or Rora ${ }^{\text {sg/sg }}$ astrocytes (orange and red circles) and were subjected to hypoxia $(6,8$, or $10 \mathrm{~h})$ followed by $24 \mathrm{~h}$ of normoxia. Neuronal death rates were estimated by quantifying LDH release (left, orange). Neuronal survival rates were estimated by counting living nuclei (manual counting) (left, purple). After $8 \mathrm{~h}$ of hypoxia, neurons were labeled with anti-MAP2 antibody (green) and nuclei were labeled with Hoechst 33258 (blue, right). The values shown are the means \pm SEM of 4 independent cultures. ( $t$ test, ${ }^{*} p<0.05$, ns, not significant). G, Losses of ROR $\alpha$ function in astrocytes and neurons have additive effects on hypoxia-induced neuronal death. Cocultures were subjected to $8 \mathrm{~h}$ of hypoxia followed by $24 \mathrm{~h}$ of normoxia. Neuronal death rates were estimated by quantifying LDH release. Values are the means \pm SEM of 4 independent cultures (ANOVA, de Scheffe, ${ }^{*} p<0.05$ ).

focused on this biological function of $\operatorname{ROR} \alpha$ in subsequent experiments.

\section{Astrocyte ROR $\alpha$ influences neuronal susceptibility to hypoxia-induced death partly by physical contact between astrocytes and neurons}

We asked whether the non-cell-autonomous neuroprotective function of ROR $\alpha$ involved the aberrant secretion of soluble factors by astrocytes, in an in vitro model based on cocultures of neurons and astrocytes without contact between the two cell types. Cocultures were prepared by combining cells of different genotypes: $\mathrm{Rora}^{+/+}$and Rora ${ }^{\text {sg/sg }}$ astrocytes with $\mathrm{Rora}^{+/+}$neurons. After hypoxia and reoxygenation, the neuronal death rates were higher (25\% higher) for cocultures with astrocytes lacking $\operatorname{ROR} \alpha(n=8$, data not shown). However, this difference was not significant. These results suggest that ROR $\alpha$ has a non-cellautonomous neuroprotective effect after hypoxia mediated mainly by changes in the contact between neurons and astrocytes. A combination of two parameters is probably responsible for altering neuronal death rates: a difference in the contact between neurons and astrocytes and a change in the level of secretion of a soluble factor by astrocytes.

\section{ROR $\alpha$ inhibits HIF- $1 \alpha$ expression in neuron/astrocyte cocultures}

We investigated the molecular mechanism underlying the role of astrocytes in the neuroprotective function of ROR $\alpha$. Oxidative stress is one of the major events leading to neuronal death after hypoxia. $\operatorname{ROR} \alpha$ has been shown to protect cortical neurons against oxidative stress-induced apoptosis by increasing the expression of antioxidant proteins, thereby reducing the accumulation of reactive oxygen species (Boukhtouche et al., 2006). We thus compared the expression of various antioxidant genes in $\mathrm{Rora}^{+/+}$and $\mathrm{Rora}^{\mathrm{sg} / \mathrm{sg}}$ neurons and astrocytes after hypoxia. Transcript levels for glutathione peroxidase 1 , 

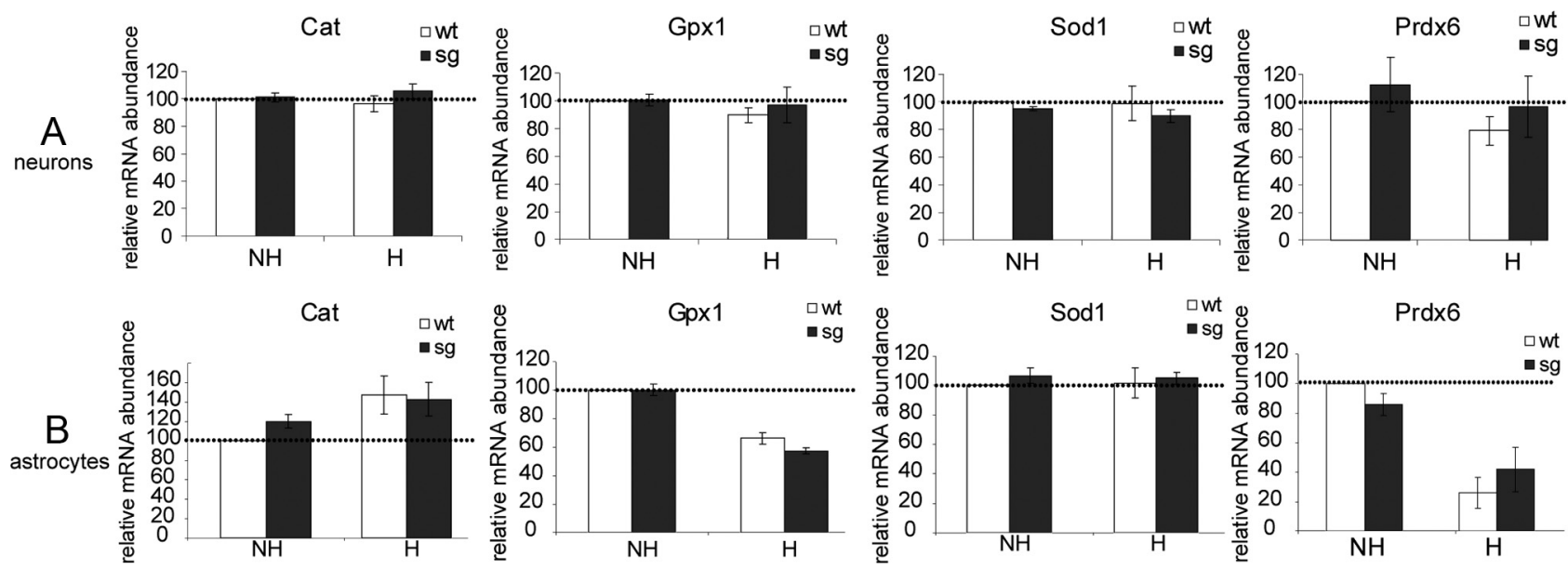

Figure 3. Antioxidant gene expression is similar between Rora ${ }^{+/+}$and Rora $^{\mathrm{sg} / \mathrm{sg}}$ neurons/astrocytes after hypoxia. Rora ${ }^{+/+}$(wt) or Rora $a^{s g / s g}(\mathrm{sg})$ neurons $(\boldsymbol{A})$ and astrocytes $(\boldsymbol{B})$ were subjected to hypoxia without reoxygenation. mRNA abundance for antioxidant genes was evaluated by real-time RT-PCR. Cat, Catalase; gpx1, glutathione peroxidase 1; sod1, superoxide dismutase 1; Prdx6, peroxiredoxin 6; $\mathrm{NH}$, non hypoxia, $\mathrm{H}$, hypoxia. Values are the means \pm SEM of 4 independent cultures.

peroxiredoxin 6, catalase, and superoxide dismutase were similar in Rora $^{+/+}$and Rora ${ }^{s g / s g}$ neurons and in Rora $^{+/+}$and Rora ${ }^{s g / s g}$ astrocytes $(n=4$, Fig. $3 A, B)$. Thus, in our model, the neuroprotective effect of $\operatorname{ROR} \alpha$ during hypoxia may not be due to a regulation of antioxidant gene expression.

Another possible explanation for the neuroprotective effect of ROR $\alpha$ is a modulation of the HIF- $1 \alpha$ pathway. Indeed, HIF- $1 \alpha$ is key regulator of oxygen homeostasis and $\operatorname{ROR} \alpha$ and HIF- $1 \alpha$ have been shown to interact in vitro (Kim et al., 2008). We investigated the regulation of HIF- $1 \alpha$ in cocultures of Rora ${ }^{+/+}$or Rora ${ }^{s g / s g}$ astrocytes and Rora $^{+/+}$neurons after $8 \mathrm{~h}$ of hypoxia by real-time PCR (Fig. 4A). Hifla gene transcript levels were similar in Rora $^{+/+}$and Rora ${ }^{\text {sg/sg }}$ cocultures and did not increase after hypoxia (Fig. $4 B$ ). Surprisingly, the post-transcriptional regulation of HIF- $1 \alpha$ differed considerably between Rora $^{+/+}$and Rora ${ }^{\text {sg/sg }}$ cocultures. Western blot analysis with relative quantification showed that the HIF- $1 \alpha$ protein was significantly more strongly induced in Rora ${ }^{s g / s g}$ cocultures $(n=5, p<0.05$, Fig. $4 C)$. We checked that this increase in HIF- $1 \alpha$ levels was correlated with an increase in its transcriptional activity, by carrying out real time PCR to analyze the transcriptional regulation of three of its targets, Vegf, Nip3, and Hk2. The induction of Vegf, Nip3, and Hk2 gene transcripts was significantly stronger in $\operatorname{Rora}^{\mathrm{sg} / \mathrm{sg}}$ cocultures than in control cultures, immediately after hypoxia $(n=5, p<$ 0.05 , Fig. $4 D$ ). In conclusion, ROR $\alpha$ in astrocytes seems to inhibit the post-transcriptional activation of HIF- $1 \alpha$ after hypoxia.

ROR $\alpha$ is upregulated by hypoxia in astrocytes and neurons but inhibits HIF-1 $\alpha$ expression only in astrocytes

Finally, we investigated the relationship between $\operatorname{ROR} \alpha$ and HIF- $1 \alpha$ during hypoxia in more detail and checked whether the inhibition of HIF- $1 \alpha$ by $\operatorname{ROR} \alpha$ was a mechanism specific to astrocytes. As $\mathrm{ROR} \alpha$ is a potential target of HIF- $1 \alpha$ (Chauvet et al., 2004), we investigated the pattern of expression of ROR $\alpha$ under hypoxia in primary cultures of neurons and astrocytes.

In neurons subjected to $7 \mathrm{~h}$ of hypoxia, Rora gene transcript levels were slightly but consistently upregulated (1.7 times higher than those in normoxic cells, $n=4$, Fig. $5 A, B$ ). Upon reoxygenation, Rora transcript levels gradually returned to basal levels: after $6 \mathrm{~h}$ of reoxygenation, transcript levels were still 1.5 times higher than those in normoxic cells (Fig. 5B). Western blot experiments revealed that $\operatorname{ROR} \alpha$ protein levels were also increased by hypoxia (they were 1.6 times higher than those in normoxic cells, $n=4$, Fig. $5 C$ ). Moreover, this regulation was specific to $\operatorname{ROR} \alpha$, as the level of transcripts for $\operatorname{ROR} \beta$, another member of the ROR subfamily expressed in the cortex, was not increased by hypoxia $(n=4$, Fig. $5 D)$. We then investigated the regulation of HIF- $1 \alpha$ in Rora $^{+/+}$and Rora ${ }^{\text {sg/sg }}$ neurons after hypoxia by real-time PCR. Quantitative analysis of Hifla gene transcripts revealed no differences between $\mathrm{Rora}^{+/+}$and $\mathrm{Rora}^{\text {sg/sg }}$ neurons (Fig. 5E). Hifla gene expression did not increase after hypoxia in either type of neurons (Fig. $5 E$ ). Similarly, the post-transcriptional regulation of HIF- $1 \alpha$ did not differ between $\mathrm{Rora}^{+/+}$and $\mathrm{Rora}^{\text {sg/sg }}$ neurons. Western blots with relative quantification showed that HIF- $1 \alpha$ protein was similarly induced after hypoxia in $\mathrm{Rora}^{+/+}$and $\operatorname{Rora}^{\text {sg/sg }}$ neurons $(n=5$, Fig. $5 F$ ). We checked that this similar pattern of HIF- $1 \alpha$ expression was correlated with similar levels of transcriptional activity, by using real-time PCR to investigate the transcriptional regulation of $V e g f, N i p 3$, and Hk2. We observed a similar induction of Vegf, Nip3, and Hk2 gene transcripts in Rora $^{+/+}$and Rora ${ }^{\text {sg/sg }}$ neurons $(n=5$, Fig. $5 G)$. In conclusion, neuronal ROR $\alpha$ does not inhibit the post-transcriptional activation of HIF- $1 \alpha$ after hypoxia.

In astrocytes, real-time PCR experiments revealed a transient upregulation of the Rora transcript by 24 h of hypoxia (levels 2.7 times higher than those in normoxic sister cultures, $n=4$, Fig. $6 A, B)$. Upon reoxygenation, Rora transcript levels rapidly returned to basal levels, demonstrating that this regulation was transient. $\operatorname{ROR} \beta$ transcripts levels were not induced by hypoxia in astrocytes $(n=4$, Fig. $6 D)$. We analyzed the regulation of $\operatorname{ROR} \alpha$ in nuclear extracts by Western blotting after hypoxia. ROR $\alpha$ protein levels were 2.6 times higher after hypoxia than in normoxic cells (Fig. 6C). Thus, similarly to what was shown in neurons, $\operatorname{ROR} \alpha$ is upregulated at the transcriptional level by hypoxia in astrocytes. Finally, the regulation of HIF- $1 \alpha$ was also analyzed in $\mathrm{Rora}^{+/+}$and Rora ${ }^{\text {sg/sg }}$ astrocytes. As in cocultures, we observed a similar pattern of transcriptional regulation of the Hif1 gene in Rora $^{+/+}$and Rora ${ }^{\text {sg/sg }}$ astrocytes, a stronger induction of the HIF- $1 \alpha$ protein correlated with an increase in the transcriptional induction of the Vegf and Nip3 genes after hypoxia in Rora $^{s g / s g}$ astrocytes than in control cultures (Fig. $6 E-G$ ). Hk2 gene expression was similar between Rora $^{+/+}$and Rora $^{\text {sg/sg }}$ astrocytes (Fig. 6G). We can therefore conclude that the differen- 
tial regulation of HIF- $1 \alpha$ by $\mathrm{ROR} \alpha$ during hypoxia is a mechanism specific to astrocytes.

\section{Discussion}

Hypoxia can have devastating consequences in the brain and the molecular mechanisms contributing to hypoxiainduced neuronal death have yet to be identified. In this study, we investigated the contribution of the nuclear receptor $\operatorname{ROR} \alpha$ to hypoxia-induced mechanisms in neurons and astrocytes. We studied the consequences of the selective loss of $\operatorname{ROR} \alpha$ function in either neurons or astrocytes using astrocyte/neuron cultures and cocultures. We showed that ROR $\alpha$ has neuroprotective properties after hypoxia through its expression both in neurons and in astrocytes (Fig. 7). We also demonstrated the upregulation of $\operatorname{ROR} \alpha$ by oxygen deprivation in both neurons and astrocytes, but showed that $\operatorname{ROR} \alpha$ had different functions in these two cell types. Indeed, ROR $\alpha$ inhibits HIF- $1 \alpha$ expression only in astrocytes, and this mechanism may account for the non-cellautonomous neuroprotective function of $\operatorname{ROR} \alpha$.

Our data reveal that the loss of $\operatorname{ROR} \alpha$ function in neurons increases neuronal susceptibility to hypoxia-induced death (Fig. 7A). ROR $\alpha$-deficient neurons displayed correct dendritic arbor development. The increase in susceptibility to hypoxia was therefore not due to changes in neuronal development in vitro. Moreover, this cell-autonomous function of $\operatorname{ROR} \alpha$ in neurons was not associated with a deregulation of antioxidant gene expression, contrary to what was previously shown with other stress (Boukhtouche et al., 2006). The target genes of $\operatorname{ROR} \alpha$ responsible for modulating neuronal survival after hypoxia have yet to be identified. The loss of ROR $\alpha$ function in astrocytes also leads to a marked increase in neuronal death after hypoxia in cocultures (Fig. $7 B$ ). Thus, ROR $\alpha$ clearly has a neuroprotective function in both neurons and astrocytes and we demonstrated that the two neuroprotective mechanisms act in an additive manner (Fig. 7C). This finding is consistent with recent studies demonstrating that astrocytes contribute to neuronal survival in many neurodegenerative or neurological disorders including Alzheimer's disease, Parkinson's disease, Huntington's disease, amyotrophic lateral sclerosis and Rett syndrome (Lobsiger and Cleveland, 2007; Ballas et al., 2009). Astrocytes have many functions that are essential for neuronal activities (control of blood flow, release of neuroprotective substances, participation in inflammatory processes etc.). However, during pathological states, the contribution of astrocytes may become either neuroprotective or harmful. For example, during ischemia, astrocytes may increase neuronal survival and plasticity by releasing erythropoietin and ATP, by producing metalloproteinases or by secreting thrombospondin (Masuda et al., 1994; Zhao et al., 2006; Liauw et al., 2008; Lin et al., 2008). However, they may also have detrimental effects through the release of neurotoxic substances such as $\mathrm{S}-100 \beta$ or nitric oxide (NO), through the release of gluta-
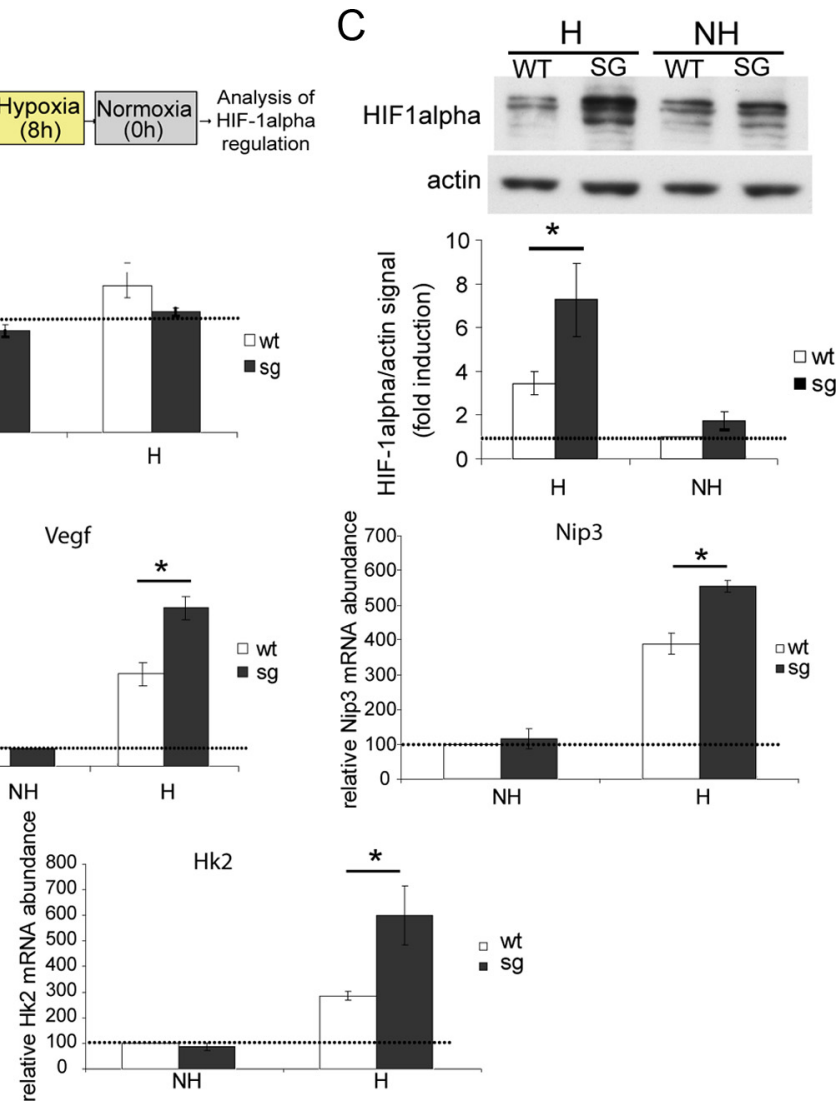

wt

Figure 4. In cocultures, ROR $\alpha$ inhibits HIF-1 $\alpha$ production after hypoxia. $\boldsymbol{A}$, Schematic diagram illustrating the experimental and Rora ${ }^{s / s g}$ cocultures after hypoxia. C, Western blot analysis (top) of the HIF-1 $\alpha$ protein in enriched nuclear extracts and relative quantification (bottom). D, Vegf, Nip3, and $H$ k2 gene transcription was analyzed by real-time RT-PCR. H, Hypoxia; $\mathrm{NH}$, non hypoxia. Values are the means \pm SEM of $4-6$ independent cultures. (Mann-Whitney, ${ }^{*} p<0.05$ ).

mate or through their contribution to the formation of brain edema (Endoh et al., 1994; Manley et al., 2000; Asano et al., 2005). The relative contribution of $\operatorname{ROR} \alpha$ in neurons and astrocytes during hypoxia and/or ischemia in vivo has now to be investigated.

Astrocytes lacking $\operatorname{ROR} \alpha$ may influence neuronal survival via several pathways. First, in normal conditions, neurons cocultured with mutant astrocytes survive but develop a more highly branched dendritic arbor. ROR $\alpha$ in astrocytes may therefore control dendritic branching. Second, during hypoxia, $\operatorname{ROR} \alpha$ in astrocytes may be beneficial to neurons through a combination of several mechanisms. Our results revealed that neurons grown on mutant astrocytes have a more complex dendritic arbor. We cannot exclude the possibility that these neurons are more vulnerable and that the increased neuronal death rates observed after hypoxia are independent of hypoxia signaling in astrocytes. In cocultures without contact between neurons and astrocytes, the loss of $\operatorname{ROR} \alpha$ function in astrocytes only slightly increased the rate of neuronal death. This increase in neuronal death was not significant and was only half that observed in cocultures with contact. Astrocytes lacking ROR $\alpha$ therefore probably influence neuronal death directly, through physical interactions with neurons, and indirectly through the release of soluble factors. ROR $\alpha$-deficient astrocytes may influence neurons directly by regulating the synaptic plasticity or different molecular pathways involved in unidentified processes in neurons, resulting in an increased neuronal death after hypoxia. $\mathrm{ROR} \alpha$-deficient astrocytes may also 


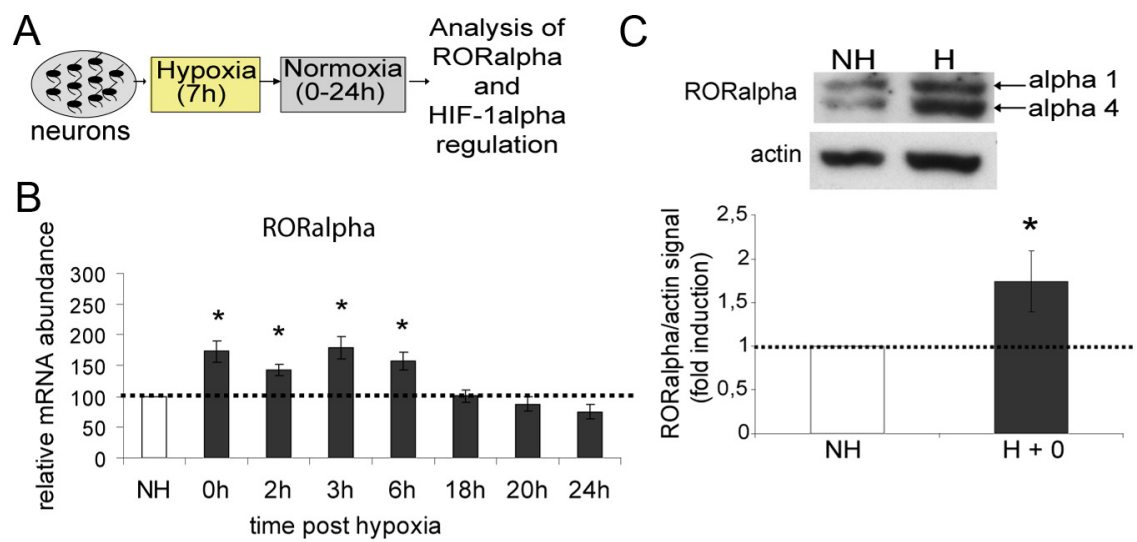

D

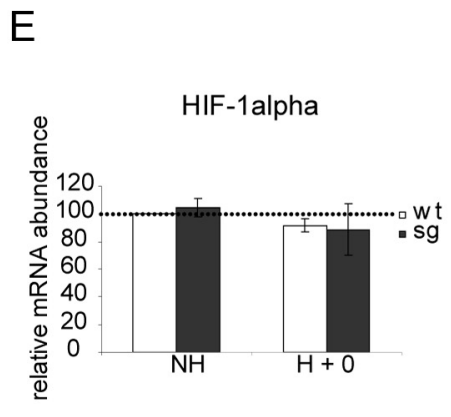

$\mathrm{F}$

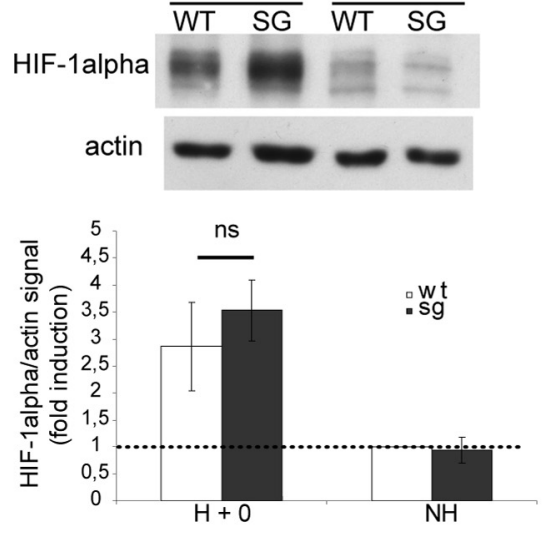

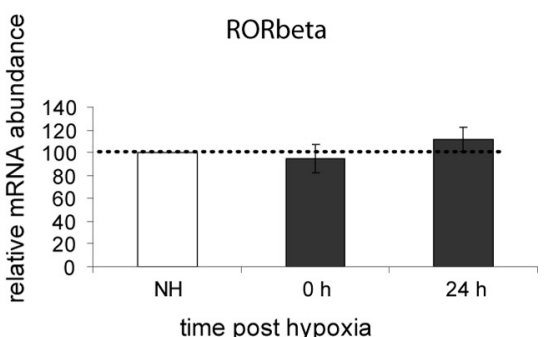
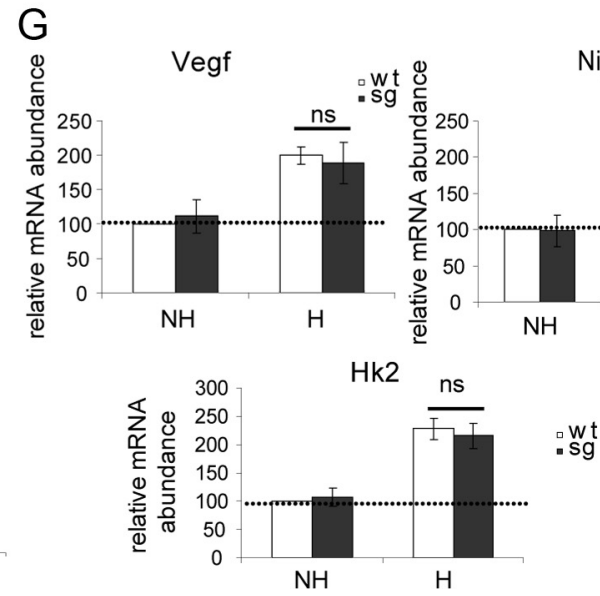

Figure 5. In neurons, ROR $\alpha$ is upregulated by hypoxia and does not preventHIF-1 $\alpha$ expression after hypoxia. $A$, Schematic diagram of the experimental protocol:Rora ${ }^{+/+}(\mathrm{wt})$ or Rora ${ }^{\mathrm{sg} / 5 g}(\mathrm{sg})$ neurons were subjected to $7 \mathrm{~h}$ of hypoxia followed by $0-24 \mathrm{~h}$ of normoxia. $\boldsymbol{B}$, Rora gene transcription was analyzed by real-time RT-PCR ( $t$ test, $\left.{ }^{*} p<0.05\right)$. C, Western blot analysis (top) of ROR $\alpha$ protein in enriched nuclear extracts from cortical neurons and relative quantification (bottom) (ttest, $\left.{ }^{*} p<0.05\right)$. D, Rorb gene transcription was analyzed by real-time RT-PCR.E, Hifla gene transcription was analyzed by real-time RT-PCR. $\boldsymbol{F}$, Western blot analysis (top) of HIF-1 $\alpha$ protein in enriched nuclear extracts and relative quantification (bottom). G, Vegf, Nip3, and Hk2 gene transcription was analyzed by real-time RT-PCR. (Mann-Whitney, ns, not significant). Values are the means \pm SEM of 4 independent cultures. $H+0$, Hypoxia without reoxygenation, NH, non hypoxia.

have a deficiency in secretion of a protective soluble factor. One candidate is IL-6 (interleukin-6), a cytokine that can promote neuronal survival. We previously demonstrated that $\mathrm{ROR} \alpha$ modulates its expression by astrocytes (Journiac et al., 2009). Alternatively, $\mathrm{ROR} \alpha$-deficient astrocytes may secrete larger amounts of factors toxic to neurons, such as NO. An analysis of the transcriptome of mutant astrocytes may help us to identify the factors involved.

Cells adapt rapidly to hypoxia, by modifying their gene expression profiles in particular. We demonstrated that, after hypoxia, ROR $\alpha$ gene expression increased markedly in neurons and astrocytes. The rapid induction of $\operatorname{ROR} \alpha$ transcripts in these two cell types indicate that $\operatorname{ROR} \alpha$ is involved in the molecular mechanisms by which cells adapt to hypoxia. $\operatorname{ROR} \alpha$ expression in astrocytes returned to baseline as soon as reoxygenation occurred, but remained high for $6 \mathrm{~h}$ in neurons. The different time course of ROR $\alpha$ expression suggests that $\mathrm{ROR} \alpha$ is involved in different pathways in neurons and in astrocytes. The induction of $\operatorname{ROR} \alpha$ transcripts after hypoxia has been reported in various cell lines including human aortic smooth muscle cells, endothelial cells, and HepG2 cells (Besnard et al., 2002; Chauvet et al., 2002, 2004; Miki et al., 2004; Kim et al., 2008). The induction of ROR $\alpha$ was attributed to an HRE (hypoxia response element) in the Rora promoter (Chauvet et al., 2004). Indeed, the authors showed by EMSA that HIF- $1 \alpha$ bound to the Rora promoter and regulated its expression. Future studies should determine whether HIF- $1 \alpha$ is one of the transcription factors responsible for modulating $\mathrm{ROR} \alpha$ expression in the brain.
As previously shown by Chavez et al. (2006), our data indicate that the fold induction of HIF- $1 \alpha$ after hypoxia is different between neurons and astrocytes. Moreover, we show here that ROR $\alpha$ inhibits HIF- $1 \alpha$ production in astrocytes at the posttranscriptional level. This inhibition is correlated with a decrease in the transcriptional induction of some HIF- $1 \alpha$ target genes such as Vegf, Nip3, and Hk2. However, Hk2 gene expression was increased in coculture with neurons and mutant astrocytes but not in cultures with mutant astrocytes (Figs. 4D, 6G). This difference may be due to the duration of hypoxia ( $8 \mathrm{~h}$ in cocultures vs $24 \mathrm{~h}$ with astrocytes) or, more likely, to the different behavior of astrocytes when they are cultured with or without neurons. The inhibition of HIF- $1 \alpha$ expression by $\operatorname{ROR} \alpha$ is specific to astrocytes because HIF- $1 \alpha$ levels were unaffected in mutant neurons. At first glance, our results may appear to contradict those of Kim et al., who showed that exogenous ROR $\alpha$ increased HIF- $1 \alpha$ levels and transcriptional activity in HepG2 and HeLa cells (Kim et al., 2008). These authors demonstrated that the knockdown of ROR $\alpha$ expression by siRNA decreased HIF- $1 \alpha$ activity (Kim et al., 2008). There may be several reasons for the difference between our results and those of Kim et al. (2008). Our experiments were performed in primary cultures of neurons and astrocytes and showed a cell specificity of the regulation of HIF- $1 \alpha$ by $\operatorname{ROR} \alpha$. We can therefore conclude that the function of ROR $\alpha$ during hypoxia differs between cell lines and primary cultures. Moreover, some of the experiments in the study by Kim et al. 

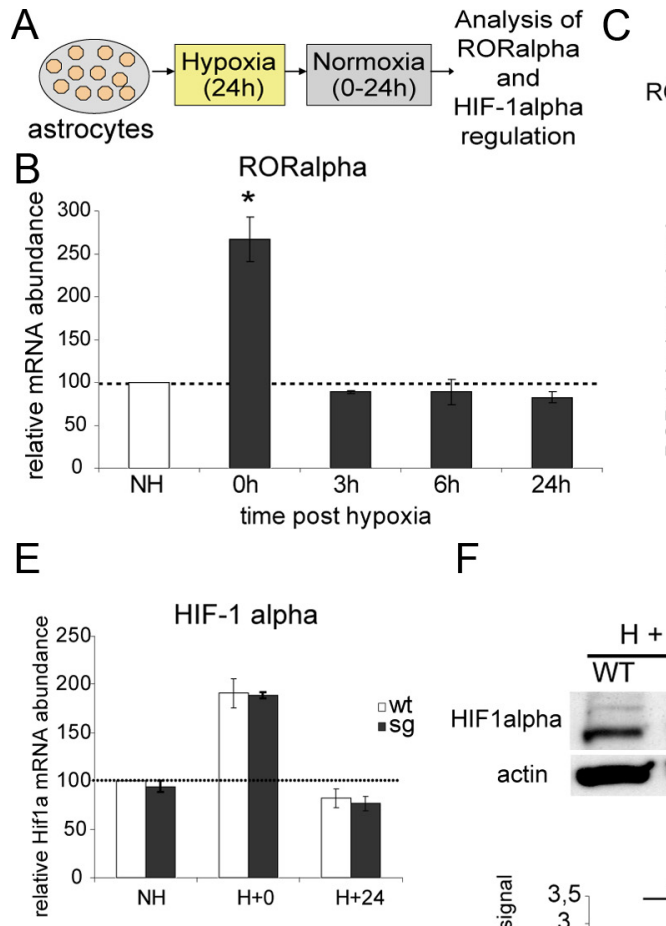

$\mathrm{F}$

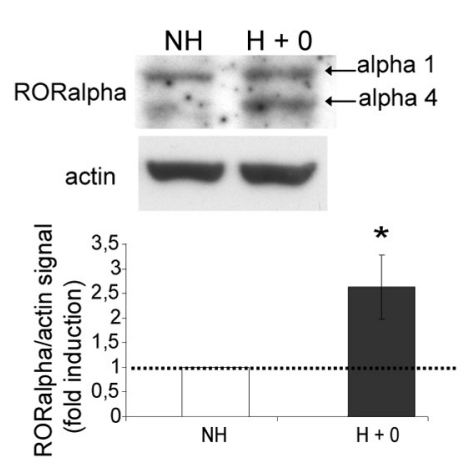

G

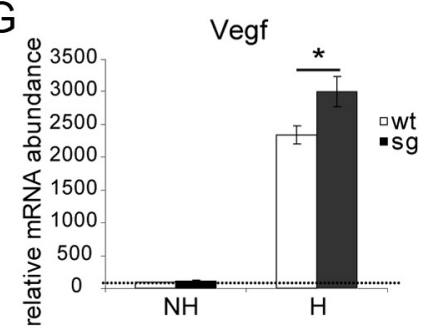

$\mathrm{D}$
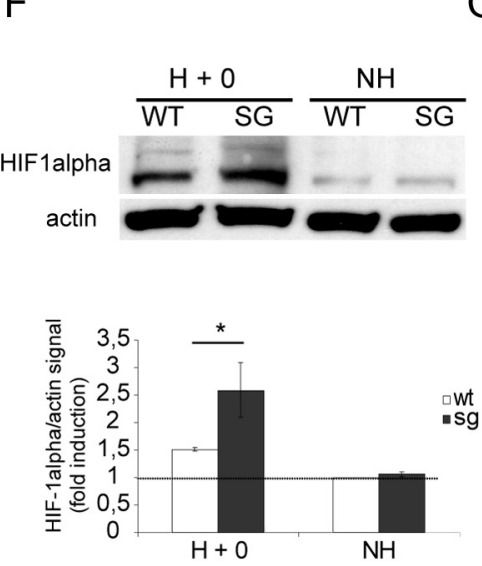

RORbeta

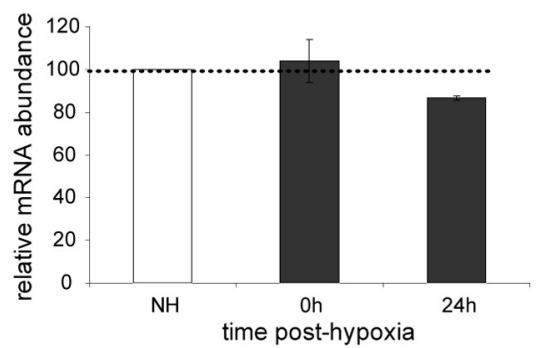

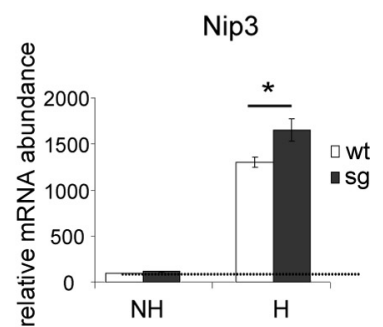

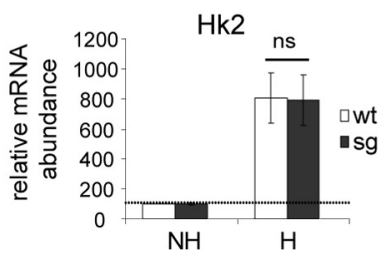

Figure 6. In astrocytes, ROR $\alpha$ is upregulated by hypoxia and inhibits HIF-1 $\alpha$ expression after hypoxia A, Schematic diagram of the experimental protocol: Rora ${ }^{+/+}$(wt) or Rora ${ }^{\text {sg/sg }}$ $(\mathrm{sg})$ astrocytes were subjected to $24 \mathrm{~h}$ of hypoxia followed by $0-24 \mathrm{~h}$ of normoxia. $\boldsymbol{B}$, Rora gene transcription was analyzed by real-time RT-PCR. ( $t$ test, $\left.{ }^{*} p<0.05\right)$. C, Western blot analysis (top) of ROR $\alpha$ protein in enriched nuclear extracts from cortical astrocytes and their relative quantification (bottom) ( $t$ test, ${ }^{*} p<0.05$ ). $\boldsymbol{D}$, Rorb gene transcription was analyzed by real-time RT-PCR. E, Hif1a gene transcription was analyzed by real-time RT-PCR in Rora ${ }^{+/+}$(wt) and Rora ${ }^{s g / s g}$ (sg) astrocytes. $\boldsymbol{F}$, Western blot analysis (top) of HIF- $1 \alpha$ protein in enriched nuclear extracts and relative quantification (bottom). G, Vegf, Nip3, and Hk2 gene transcription was analyzed by real-time RT-PCR in Rora ${ }^{+/+}$and Rora ${ }^{\text {sg/sg }}$ cells (MannWhitney, ${ }^{*} p<0.05$, ns, not significant). The values shown are the means \pm SEM of $4-6$ independent cultures. $\mathrm{H}+0$, Hypoxia without reoxygenation; $\mathrm{H}+24$, hypoxia and $24 \mathrm{~h}$ of reoxygenation; $\mathrm{NH}$, non hypoxia.

(2008) included the use of melatonin to activate $\operatorname{ROR} \alpha$. This putative ligand of $\operatorname{ROR} \alpha$ remains controversial and additional experiments are thus required to determine the relationship between $\operatorname{ROR} \alpha$ and HIF- $1 \alpha$ in these cell lines (Jetten, 2009).

Could the regulation of HIF- $1 \alpha$ by ROR $\alpha$ explain the non-cell-autonomous neuroprotective function of $\operatorname{ROR} \alpha$ in astrocytes? The effect of HIF- $1 \alpha$ on neuronal viability remains a matter of debate. For example, two groups used the same murine model to invalidate HIF- $1 \alpha$ expression in neurons (floxed HIF-1 mice crossed with CAM-Cre mice (Cre recombinase under the control of the calcium calmodulindependent kinase promoter)). They observed opposite effects after hypoxia or ischemia: a deleterious or a protective effect of HIF- $1 \alpha$ expression for neuronal survival (Helton et al., 2005; Baranova et al., 2007). There may be several reasons for this difference in findings. First, the type of stimulus used differed in the two studies. Second, the

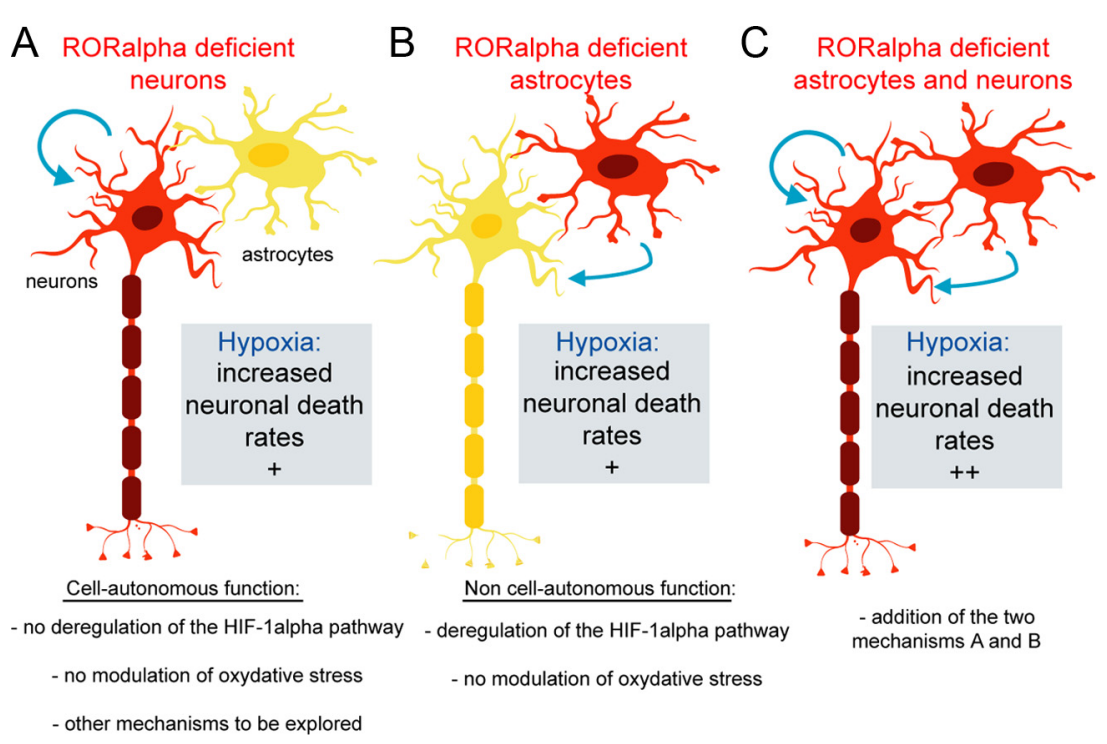

Figure 7. Cell-autonomous and non-cell-autonomous neuroprotective functions of $\operatorname{ROR} \alpha$ during hypoxia. $\boldsymbol{A}, \mathrm{ROR} \alpha$ deficient neurons have increased neuronal death rates after hypoxia. $\boldsymbol{B}$, The absence of $\mathrm{ROR} \alpha$ in astrocytes does not modify astrocytic survival but neuronal survival after hypoxia. ROR $\alpha$ inhibits HIF- $1 \alpha$ expression in astrocytes. $C$, When both neurons and astrocytes are deficient for $\operatorname{ROR} \alpha$, the neuronal death rates are still increased after hypoxia compared with conditions $A$ and $B$. 
degree and cellular specificity of recombination differed between the two studies. Interestingly, HIF- $1 \alpha$ function may be cell-specific. Indeed, G. Vangeison et al. investigated the impact of a loss of HIF- $1 \alpha$ function in either neurons or astrocytes after hypoxia using neuron/astrocyte cocultures. The loss of HIF- $1 \alpha$ function in neurons had a deleterious effect on neurons, whereas the loss of HIF- $1 \alpha$ function in astrocytes had a protective effect on neurons (Vangeison et al., 2008). Thus, HIF-1 $\alpha$ is deleterious for neurons when produced by astrocytes and neuroprotective when produced by neurons (Vangeison et al., 2008). In our experiments, the inhibition of HIF- $1 \alpha$ production by ROR $\alpha$ in astrocytes may account for the neuroprotective function of ROR $\alpha$ in astrocytes.

In conclusion, in this study we provide evidence that $\operatorname{ROR} \alpha$ is an important molecular player during hypoxia. Most studies investigating the molecular mechanisms underlying hypoxia-induced cell death have focused on neurons. However, astrocytes are actively involved in the response to hypoxia with some astrocyte functions increasing and others decreasing neuronal viability. This new molecular mechanism highlights the importance of astrocytes and of $\operatorname{ROR} \alpha$ in hypoxia-mediated cell death.

\section{References}

Asano T, Mori T, Shimoda T, Shinagawa R, Satoh S, Yada N, Katsumata S, Matsuda S, Kagamiishi Y, Tateishi N (2005) Arundic acid (ONO-2506) ameliorates delayed ischemic brain damage by preventing astrocytic overproduction of S100B. Curr Drug Targets CNS Neurol Disord 4:127-142.

Ballas N, Lioy DT, Grunseich C, Mandel G (2009) Non-cell autonomous influence of MeCP2-deficient glia on neuronal dendritic morphology. Nat Neurosci 12:311-317.

Baranova O, Miranda LF, Pichiule P, Dragatsis I, Johnson RS, Chavez JC (2007) Neuron-specific inactivation of the hypoxia inducible factor $1 \alpha$ increases brain injury in a mouse model of transient focal cerebral ischemia. J Neurosci 27:6320-6332.

Besnard S, Heymes C, Merval R, Rodriguez M, Galizzi JP, Boutin JA, Mariani J, Tedgui A (2002) Expression and regulation of the nuclear receptor RORalpha in human vascular cells. FEBS Lett 511:36-40.

Boukhtouche F, Vodjdani G, Jarvis CI, Bakouche J, Staels B, Mallet J, Mariani J, Lemaigre-Dubreuil Y, Brugg B (2006) Human retinoic acid receptorrelated orphan receptor alpha1 overexpression protects neurones against oxidative stress-induced apoptosis. J Neurochem 96:1778-1789.

Bruick RK, McKnight SL (2001) A conserved family of prolyl-4-hydroxylases that modify HIF. Science 294:1337-1340.

Chauvet C, Bois-Joyeux B, Danan JL (2002) Retinoic acid receptor-related orphan receptor (ROR) alpha4 is the predominant isoform of the nuclear receptor RORalpha in the liver and is up-regulated by hypoxia in HepG2 human hepatoma cells. Biochem J 364:449-456.

Chauvet C, Bois-Joyeux B, Berra E, Pouyssegur J, Danan JL (2004) The gene encoding human retinoic acid-receptor-related orphan receptor alpha is a target for hypoxia-inducible factor 1. Biochem J 384:79-85.

Chávez JC, Agani F, Pichiule P, LaManna JC (2000) Expression of hypoxiainducible factor-1alpha in the brain of rats during chronic hypoxia. J Appl Physiol 89:1937-1942.

Chavez JC, Baranova O, Lin J, Pichiule P (2006) The transcriptional activator hypoxia inducible factor 2 (HIF-2/EPAS-1) regulates the oxygendependent expression of erythropoietin in cortical astrocytes. J Neurosci 26:9471-9481.

Desclaux M, Teigell M, Amar L, Vogel R, Gimenez Y Ribotta M, Privat A, Mallet J (2009) A novel and efficient gene transfer strategy reduces glial reactivity and improves neuronal survival and axonal growth in vitro. PLoS One 4:e6227.

Doulazmi M, Frédéric F, Lemaigre-Dubreuil Y, Hadj-Sahraoui N, DelhayeBouchaud N, Mariani J (1999) Cerebellar Purkinje cell loss during life span of the heterozygous staggerer mouse (Rora $(+) / \operatorname{Rora}(\mathrm{sg}))$ is genderrelated. J Comp Neurol 411:267-273.

Endoh M, Maiese K, Wagner J (1994) Expression of the inducible form of nitric oxide synthase by reactive astrocytes after transient global ischemia. Brain Res 651:92-100.

Gold DA, Gent PM, Hamilton BA (2007) ROR alpha in genetic control of cerebellum development: 50 staggering years. Brain Res 1140:19-25.
Hamilton BA, Frankel WN, Kerrebrock AW, Hawkins TL, FitzHugh W, Kusumi K, Russell LB, Mueller KL, van Berkel V, Birren BW, Kruglyak L, Lander ES (1996) Disruption of the nuclear hormone receptor RORalpha in staggerer mice. Nature 379:736-739.

Helton R, Cui J, Scheel JR, Ellison JA, Ames C, Gibson C, Blouw B, Ouyang L, Dragatsis I, Zeitlin S, Johnson RS, Lipton SA, Barlow C (2005) Brainspecific knock-out of hypoxia-inducible factor- $1 \alpha$ reduces rather than increases hypoxic-ischemic damage. J Neurosci 25:4099-4107.

Ino H (2004) Immunohistochemical characterization of the orphan nuclear receptor ROR alpha in the mouse nervous system. J Histochem Cytochem 52:311-323.

Jaakkola P, Mole DR, Tian YM, Wilson MI, Gielbert J, Gaskell SJ, Kriegsheim Av, Hebestreit HF, Mukherji M, Schofield CJ, Maxwell PH, Pugh CW, Ratcliffe PJ (2001) Targeting of HIF-alpha to the von Hippel-Lindau ubiquitylation complex by O2-regulated prolyl hydroxylation. Science 292:468-472.

Jetten AM (2009) Retinoid-related orphan receptors (RORs): critical roles in development, immunity, circadian rhythm, and cellular metabolism. Nucl Recept Signal 7:e003.

Journiac N, Jolly S, Jarvis C, Gautheron V, Rogard M, Trembleau A, Blondeau JP, Mariani J, Vernet-der Garabedian B (2009) The nuclear receptor ROR(alpha) exerts a bi-directional regulation of IL- 6 in resting and reactive astrocytes. Proc Natl Acad Sci U S A 106:21365-21370.

Kallen JA, Schlaeppi JM, Bitsch F, Geisse S, Geiser M, Delhon I, Fournier B (2002) X-ray structure of the hRORalpha LBD at $1.63 \mathrm{~A}$ : structural and functional data that cholesterol or a cholesterol derivative is the natural ligand of RORalpha. Structure 10:1697-1707.

Kim EJ, Yoo YG, Yang WK, Lim YS, Na TY, Lee IK, Lee MO (2008) Transcriptional activation of HIF-1 by RORalpha and its role in hypoxia signaling. Arterioscler Thromb Vasc Biol 28:1796-1802.

Lando D, Peet DJ, Gorman JJ, Whelan DA, Whitelaw ML, Bruick RK (2002) FIH-1 is an asparaginyl hydroxylase enzyme that regulates the transcriptional activity of hypoxia-inducible factor. Genes Dev 16:1466-1471.

Liauw J, Hoang S, Choi M, Eroglu C, Choi M, Sun GH, Percy M, WildmanTobriner B, Bliss T, Guzman RG, Barres BA, Steinberg GK (2008) Thrombospondins 1 and 2 are necessary for synaptic plasticity and functional recovery after stroke. J Cereb Blood Flow Metab 28:1722-1732.

Lin JH, Lou N, Kang N, Takano T, Hu F, Han X, Xu Q, Lovatt D, Torres A, Willecke K, Yang J, Kang J, Nedergaard M (2008) A central role of connexin 43 in hypoxic preconditioning. J Neurosci 28:681-695.

Lobsiger CS, Cleveland DW (2007) Glial cells as intrinsic components of noncell-autonomous neurodegenerative disease. Nat Neurosci 10:1355-1360.

Manley GT, Fujimura M, Ma T, Noshita N, Filiz F, Bollen AW, Chan P, Verkman AS (2000) Aquaporin-4 deletion in mice reduces brain edema after acute water intoxication and ischemic stroke. Nat Med 6:159-163.

Masuda S, Okano M, Yamagishi K, Nagao M, Ueda M, Sasaki R (1994) A novel site of erythropoietin production. Oxygen-dependent production in cultured rat astrocytes. J Biol Chem 269:19488-19493.

Miki N, Ikuta M, Matsui T (2004) Hypoxia-induced activation of the retinoic acid receptor-related orphan receptor alpha4 gene by an interaction between hypoxia-inducible factor-1 and Sp1. J Biol Chem 279:15025-15031.

Pfaffl MW (2001) A new mathematical model for relative quantification in real-time RT-PCR. Nucleic Acids Res 29:e45.

Rempe DA, Lelli KM, Vangeison G, Johnson RS, Federoff HJ (2007) In cultured astrocytes, p53 and MDM2 do not alter hypoxia-inducible factor-1alpha function regardless of the presence of DNA damage. J Biol Chem 282:16187-16201.

Semenza GL (2000) HIF-1: mediator of physiological and pathophysiological responses to hypoxia. J Appl Physiol 88:1474-1480.

Sharp FR, Bernaudin M (2004) HIF1 and oxygen sensing in the brain. Nat Rev Neurosci 5:437-448.

Vangeison G, Carr D, Federoff HJ, Rempe DA (2008) The good, the bad, and the cell type-specific roles of hypoxia inducible factor- $1 \alpha$ in neurons and astrocytes. J Neurosci 28:1988-1993.

Wang Y, Kumar N, Solt LA, Richardson TI, Helvering LM, Crumbley C, Garcia-Ordonez RD, Stayrook KR, Zhang X, Novick S, Chalmers MJ, Griffin PR, Burris TP (2010) Modulation of retinoic acid receptorrelated orphan receptor alpha and gamma activity by 7-oxygenated sterol ligands. J Biol Chem 285:5013-5025.

Zhao BQ, Wang S, Kim HY, Storrie H, Rosen BR, Mooney DJ, Wang X, Lo EH (2006) Role of matrix metalloproteinases in delayed cortical responses after stroke. Nat Med 12:441-445.

Zhao Y, Rempe DA (2010) Targeting astrocytes for stroke therapy. Neurotherapeutics 7:439-451. 